\title{
Treinamento de Pessoal em Emprêsas Industriais
}

\author{
Paulo Novaes
}

\section{INTRODUÇÃO}

$\mathrm{N}_{\text {s }}$

AS notas que se seguem, preparadas para o curso de Assistentes de Direção, organizado pelo DR do SENAI do Rio Grande Sul, o autor procurou expor, de forma sintética, o que a experiência de alguns anos no campo do treinamento lhe indicou como sendo mais útil.

Foram evitados os assuntos que já se acham expostos em publicações do SENAI e de outras entidades. Também não se entrou em detalhes que poderiam alongar o trabalho sem beneficio real. E' preferivel fixar bem a razão de ser dos métodos, e deixar os detalhes a cargo de coordenadores de treinamento com a necessária capacidade. Porque se não tiverem capacidade, também não adiantará dar os detalhes.

Os exemplos práticos que forem aplicáveis serão fornecidos separadamente.

\section{O QUE É O TREINAMENTO}

Os resultados obtidos por uma emprêsa dependem, em primeiro lugar, da perfeição com que cada um de seus funcionários, compreende e executa as suas tarefas e contribui para a harmonia e a eficiência do conjunto.

Se deixarmos a cada um a tarefa de melhorar a sua atuação dentro da emprêsa, usando para isso apenas os seus recursos individuais, o resultado será, evidentemente, precário. E' preciso que a própria emprêsa se interesse por essa melhoria, dando a cada um a oportunidade de se aperfeiçoar para que possa trabalhar melhor, contribuir para os objetivos comuns, e progredir individualmente. 


\section{Como iniciar um programa de treinamento}

Não se pode esperar de um programa de treinamento o desejado sucesso sem contar com apoio da direção da Emprêsa e o interêsse do pessoal de tôdas as categorias. Cumpre, em primeiro lugar, despertar êsse interêsse e estimulá-lo para que exista um desejo real de proporcionar e receber treinamento.

E' de capital importância o exame cuidadoso de todos os fatôres que, em qualquer emprêsa, influenciam o interêsse individual dos que serão afetados pelo treinamento. Os chefes estarão interessados em obter um maior rendimento do seu pessoal ou na solução dos seus problemas da falta de pessoal habilitado, e uma vez que estejam convencidos de que o treinamento pode solucionar estas questões, procurarão conhecer qual o modo mais simples e eficiente de executar o treinamento necessário. Os empregados estarão interessados nas persepctivas de melhoria individual, e poderão ver no treinamento uma porta aberta para um progresso futuro.

- O interêsse geral pelo treinamento dependerá das perspectivas oferecidas ao pessoal, pela emprêsa, em matéria de progresso e promoção. Não se pode esperar sucesso de um programa de treinamento, se a emprêsa não oferecer a seus empregados a segurança de um trabalho e condições de vida cada vez melhores.

\section{Os objetivos do treinamento}

E' preciso não esquecer que o treinamento não é um objetivo em si mesmo, mas tão-sòmente, um meio eficaz para alcançar os objetivos da emprêsa, através do desenvolvimento seguro das habilidades e das atitudes do seu pessoal.

O treinamento será tanto mais eficaz, em relação aos objetivos da emprêsa, quanto mais integrado estiver nas suas operações normais, no seu trabalho diário.

Um treinamento realizado eventualmente, fora do programa normal de trabalho da emprêsa, pode proporcionar um estimulo passageiro, mas também pode ocasionar um desânimo, se êle não corresponder a um objetivo sincero e permanente da direção.

\section{Os métodos de treinamento}

Quando se fala de treinamento, a maioria das pessoas pensa logo em cursos, aulas, escolas e professôras. Os métodos escolares têm sua aplicação, mas treinar é uma atividade muito mais ampla. 
Existem muitos métodos de treinamento, aplicados a diferentes situações, como por exemplo:

— instrução individual no trabalho;

- instrução em grupo;

- reunião;

— estágio;

- curso por correspondência.

Êsses métodos podem ser usados isoladamente ou combinados, mas sempre de acôrdo com uma programação prévia, e para atingir um objetivo especifico.

Qualquer que seja o método, dois elementos são essenciais:

- $\mathrm{o}$ instrutor;

- material de ensino.

$O$ instrutor deve ter um bom conhecimento do assunto e estar preparado para ensiná-lo corretamente. O material de ensino deve ser cuidadosamente preparado para que a instrução seja eficiente. Em qualquer emprêsa, os manuais de serviço representam um instrumento muito útil para o ensino, e devem ser sempre preparados tendo essa finalidade em vista. Além do material, muitas vêzes é necessário que existam instalações ou locais próprios para o treinamento.

\section{A coordenação do treinamento}

Para que atinja os objetivos certos, com os métodos mais convenientes, é preciso trabalhar organizadamente. Assim, para cada treinamento, dève ser preparado um plano. O conjunto dêstes planos é que constitui o programa de treinamento da emprêsa. Para que os planos sejam preparados corretamente, e estabelecida uma ordem de prioridade na sua programação, é preciso que haja, em cada emprêsa, uma coordenação do treinamento. Essa coordenação pode ser exercida por uma pessoa ou por um grupo, mas é indispensável.

\section{O treinamento deve estat relacionado com as necessidades futuras do pessoal}

O treinamento deve ter em vista não só as necessidades atuais como também as necessidades futuras da emprêsa em matéria de pessoal. E' preciso que sejam conhecidos os planos para o futuro, elaborados pela administração, para promover os treinamentos necessários. Seria um êrro dos mais graves- se os administradores se preocupassem somente com os problemas do mo- 
mento. Alguns treinamentos são, necessàriamente, muito demo rados, exigindo períodos de prática entre cada uma de suas fases.

A preparação de pessoal para chefia pode exigir muitos anos e deve ser começada com muita antecedência, tendo em vista as necessidades futuras da emprêsa. E' fácil compreender que o sucesso futuro da emprêsa depende da preparação de um quadro de pessoal que reúna as qualidades necessárias. Nessa preparação, o treinamento desempenha um papel muito importante.

\section{Serviços em que se aplica o treinamento}

O treinamento deve-se estender a todo o pessoal da emprêsa, em tôdas as categorias, cargos e funções. Todo aquêle que estiver sendo submetido a treinamento é chamado de treinando, e tanto pode ser um gerente, como um operário semiqualificado.

O treinamento deve ser aplicado desde o instante em que o nôvo funcionário é admitido no emprêgo, e deve continuar durante o seu tempo de serviço. Naturalmente, isto não se fará contìnuamente, mas por doses periódicas, de acôrdo com um programa pré-estabelecido.

\section{COMO DETERMINAR AS NECESSIDADES DO TREINAMENTO}

O treinamento eficiente em uma emprêsa só pode ser conseguido com base em uma correta interpretação das necessidades reais de treinamento. Não é suficiente, embora necessária, a simples compreensão de que tôdas as emprêsas necessitam de treinamento de seu pessoal. E' importante reconhecer quais os problemas que indicam essa necessidade. Os fatos que indicam as necessidades indicarão também muitos dos fatôres que deverão ser considerados na organização do treinamento.

\section{Avaliação das necessidades de treinamento}

De um modo geral, há duas pesquisas a serem feitas: mento.

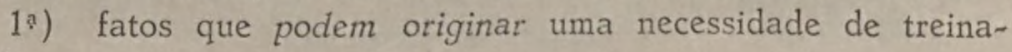

$2^{\text {s) }}$ problemas que indicam a necessidade do treinamento.

Entre os fatos que podem originar uma necessidade de treinamento estão:

a) admissão de novos empregados;

b) diminuição do número de empregados; 
c) mudanças nas rotinas de serviço;

d) expansão de serviços;

e) utilização de técnicas e equipamentos novos.

Problemas que indicam a necessidade de treinamento podem ser, entre outros:

19) baixa produtividade;

2.) avarias freqüientes em máquinas e instalações;

3:) atraso das informações e erros na execução de ordens;

4\%) desperdícios ou rejeições em excesso;

5:) pouco interêsse pelo trabalho.

A pesquisa das necessidades de treinamento deve ser feita por todos os chefes e supervisores, que para isso devem ser treinados pelo coordenador. E' muito fácil dizer que os funcionários ou empregados precisam melhorar, mas é muito difícil precisar em que, e para que, êles devem ser melhorados.

A dificuldade mais freqüente é que os chefes e supervisores não têm uma idéia clara do que seja o treinamento. Pensam logo em cursos longos, em estudos escolares, e não se lembram que, na maior parte dos casos, trata-se apenas de dar uma instrução curta, simples e clara, e que faz parte das suas tarefas normais.

Trabalho do coordenador no levantamento das necessidades de treinamento

O coordenador deve treinar os chefes e supervisores a identificar corretamente as necessidades de treinamento e a escolher o método mais simples para soluciná-las. Ao discutir o assunto êle pode considerar os seguintes pontos:

19) que é, exatamente, o problema?

$\left.2^{\circ}\right)$ onde foi assinalado em $1^{\circ}$ lugar?

3:) ocorre também em outro setor?

4.) fará parte de um problema mais geral?

5\%) deverá ser atendida a necessidade de treinamento separadamente ou em combinação com outros?

$\left.6^{\circ}\right)$ de quantas pessoas se trata?

7॰) qual o tempo disponível para o treinamento?

8) a necessidade é temporária ou permanente?

90) a necessidade é imediata?

10\%) qual o custo provável do treinamento?

118) quem deve executar o treinamento?

12.) é preciso preparar material de treinamento?

13\%) é preciso tomar alguma providência, ou consultar mais alguém antes de prosseguir no estudo? 
Uma vez definida a necessidade de treinamento, a urgência do seu atendimento e as pessoas que devem colaborar na solução, pode-se passar à preparação do plano de treinamento.

E' preciso não esquecer que o treinamento não é um objetivo da atividade da emprêsa, mas tão-sòmente um modo eficaz de conseguir o desenvolvimento das atividades da emprêsa e do equilíbrio necessário ao seu bom funcionamento. O treinamento será, pois, tanto mais eficaz quanto mais integrado estiver nos programas de trabalho da emprêsa.

\section{Planos de treinamento}

As vêzes, o estudo de uma necessidade de treinamento revela que o problema pode ser resolvido por único plano. Outras vêzes, é preferível programar o trabalho de treinamento, subdividindo-o em diversos planos, de acôrdo com as possibilidades e disponibilidades de tempo e pessoal.

Cada plano deve conter os seguintes elementos:

1\%) qual o problema que determinou a necessidades de treinamento;

2) qual o objetivo do treinamento, isto é, que conhecimentos ou habilidades ou atitudes se pretende transmitir ao treinando;

3) quem vai ser treinado e quais os métodos eventuais de seleção;

4.) qual o método de treinamento que vai ser usado;

5\%) qual a época, local e demais detalhes relativos à realização do treinamento;

6?) quais os responsáveis pela execução do treinamento;

7॰) qual o custo do treinamento;

8\%) como vai ser verificado o resultado obtido com o treinamento;

9०) quais as providências complementares necessárias, tais como a preparação de material de instrução, contrato de instrutores, preparação de locais adequados, etc.

O plano de treinamento deve ser aprovado pelo chefe dos treinandos, pelo coordenador do treinamento da emprêsa, e pela direção-geral da mesma.

\section{III}

MÉTODOS DE TREINAMENTO

Os métodos de treinamento podem-se classificar de muitas maneiras diferentes. Para nossos fins preferimos fazer uma di- 
visão inicial, considerando primeiro os métodos em que há uma predominância da "instrução", por meios mecânicos, isto é, sem a atuação pessoal de um treinador.

\section{Processos gráficos}

O primeiro dêsses métodos é a instrução por escrito; o livro, o folheto, ou a simples fôlha de instrução. São processos simples e econômicos, cuja aplicação tanto pode ser individual, através de um impresso destinado ao uso pessoal do treinando, como coletivo, através de cartazes. Um exemplo é o uso de instruções e de cartazes, para melhoria de condições de segurança no trabalho.

A preparação de material escrito, ou material gráfico em geral, demanda muita atenção para que se obtenha resultado. $\mathrm{E}^{\prime}$ importante, em primeiro lugar, que o material seja legivel, isto é, seja impresso em tipos de tamanho suficiente para poder ser usado nas condições de iluminação, distância e acuidade visual, compativeis com as situações em que vão ser usados. E' um êrro freqüente, por exemplo, a impressão de manuais de instruções com tipo muito pequeno, cuja leitura é extremamente difícil, senão impossivel, para maior parte das pessoas de certa idade. Outro êrro é a preparação de cartazes copiados em papel Ozalid e colocados em locais expostos à luz solar, os quais em pouco tempo estão tão desbotados que ficam ilegiveis.

Outros métodos mais elaborados são o cinema e as projeções em geral, acompanhadas, ou não, de reprodução sonora. Êsses são métodos caros e de uso pouco freqüente. A sua aplicação só é verdadeiramente eficiente quando se trata de instruir grandes quantidades de pessoas, ràpidamente, em assuntos limitados.

\section{Instrução otal}

A maior parte dos métodos de treinamento rstá baseada no trabalho pessoal de um instrutor ou treinador. A instrução é transmitida por explicação oral e, muitas vêzes, por demonstração prática.

Esse trabalho é acompanhado, em geral, pelo fornecimento de material escrito, para estudo do treinando. E' essencial, na maior parte dos casos, a ação do treinador no acompanhamento do treinando, para verificar se êle assimilou a instrução recebida e corrigir os seus erros eventuais.

A instrução pode ser em grupo ou individual. O caso mais freqüente é o da instrução individual. Para dar um melhor resultado, é preciso que quem dá a instrução esteja preparado para 
isso, tendo feito, por exemplo, um curso de "ensino correto de certo trabalho".

A instrução em grupo pode ser feito por dois processos, a reunião de instrução e a aula. A reunião de instrução deve ser conduzida de acôrdo com determinadas regras, necessárias para garantir o sucesso do método. Em geral as reuniões são realizadas com 8 a 10 pessoas e duram de 2 a 3 horas. E' o método mais eficiente quando se trata de assuntos que exijam modificações de atitudes. Todos os supervisores, de nível médio e alto, de uma emprêsa devem ser capazes de conduzir uma reunião de treinamento.

A aula é utilizada quando há necessidade de transmitir grande quantidade de informações técnicas, acompanhadas de explicações que facilitem sua compreensão, a grupos numerosos, por exemplo: de 20 a 40 alunos. A aula em geral faz parte de uma sequiência de atividades de treinamento, que se complementam umas as outras, tais como: demonstrações, leituras, reuniões, exercícios práticos.

A conferência é usada para exposição de um tema determinado, de uma única vez, e para um auditório maior. E' como se fôsse uma aula isolada e sem que exista obrigação para os alunos de estudo complementar a respeito do assunto exposto.

\section{Aprendizagem}

O têrmo aprendizagem deve ser usado para um tipo especial de treinamento: a formação de operários qualificados. No Brasil, quando a aprendizagem é dada a menores, de 14 a 18 anos, o empregador goza de certos favores que compensam o seu esfôrço para a formação de pessoal qualificado e que são a possibilidade de pagar até $50 \%$ menos que o salário minimo e a isenção do serviço militar para o aprendiz.

A aprendizagem para ter valor legal deve obedecer a certas regras, estabelecidas pelo Ministério do Trabalho, e cuja aplicação está confiada à orientação do SENAI.

Esse método de treinamento tem grande valor para a formação de pessoal qualificado em ofícios industriais, para cujo exercício é preciso ter conhecimentos técnicos e uma grande habilidade profissional, mas, para que a aprendizagem possa ser eficaz, é preciso que seja muito bem planejada e controlada. O SENAI conta hoje com especialistas que podem ajudar a emprêsa a organizar a aprendizagem e dela tirar o melhor resultado.

Quase sempre, para que a aprendizagem seja verdadeiramente eficiente, é preciso recorrer a uma escola para completar 
o preparo técnico dos aprendizes. Hoje há escolas técnicas oficiais e do SENAI em quase tôda parte e é muito fácil conseguir o auxílio necessário.

A emprêsa deve sempre considerar a utilização de pessoal formado pelas escolas do SENAI e oficiais, mas ai trata-se mais de um problema de seleção, e não de treinamento dentro da emprêsa. Essas escolas são, hoje, muito eficientes e prestam um grande serviço. Isso não é motivo, contudo, para que grandes emprêsas procurem montar escolas primárias, do mesmo tipo. Só em casos especialissimos isso seria possivel. Uma escola técnica é um estabelecimento que, para ser eficiente, é de custo elevadissimo, muito dificilmente suportado por uma emprêsa.

\section{Treinamento de supervisão e chefia}

Conseguir chefia e supervisão eficiente é dos maiores problemas de qualquer emprêsa. Um bom supervisor deve ter qualidades pessoais inatas, que são muito difíceis de definir porque cada emprêsa tem uma personalidade própria, métodos de trabalho e critério de julgamento que fazem com que um bom supervisor, para ela, muitas vêzes seja um mau supervisor noutra emprêsa.

Está provado que a boa supervisão e a boa chefia só se conseguem através de seleção e treinamento cuidadosos e contínuos. Pode-se mesmo admitir que $50 \%$ ou mais das despesas de treinamento tendem a se realizar nesse campo.

\section{Treinamento da supervisão de primeira linha}

A maioria de supervisores de primeira linha são escolhidos entre empregados que se destacaram na execução de suas tarefas, por terem revelado alguma qualidade acima da média. Poder ser que u’n operário tenha demonstrado maior rapidez de compreensão na execução de ordens de serviço, maior capacidade para melhorar métodos de trabalho, maior senso de responsabilidade, etc. Por uma razão qualquer, é levado a uma posição de chefia de grupo, torna-se responsável pelo trabalho de outros. Para que possa tornar-se um bom supervisor, deve no mínimo, além das qualidades pessoais óbvias para tais funções, possuir os seguintes atributos:

19) conhecer as normas e regulamentos da emprêsa;

29) conhecer os elementos técnicos inerentes ao trabalho que vai supervisionar;

3) ser capaz de transmitir ordens e instruir o pessoal sôbre essas ordens; 
4.) ser capaz de melhorar constantemente os métodos e condições de trabalho;

Todos êsses pontos devem ser objeto de treinamento sistemático. $\mathrm{E}^{\prime}$ o que geralmente se chama de treinamento básico de superivsão, e o método mais prático para efetuá-lo é através de reuniões conduzidas por instrutores especialmente preparados para isso.

Um bom supervisor precisa ser constantemente acompanhado e o seu treinamento complementado de tempos a tempos, para que êle possa progredir. O coordenador de treinamento da emprêsa deve ter um programa continuo de melhoramento na supervisão de $1^{\text {a }}$ linha.

\section{Treinamento de chefia}

A supervisão de nivel mais alto, até a chefia de administração geral, exige uma preparação cuidadosa. Um dos maiores problemas de uma emprêsa é preparar os seus futuros chefes, porque êsse é um processo que deve levar necessàriamente muito tempo.

A primeira providência que uma emprêsa que tem planos de expansão para o futuro deve tomar é a de conseguir para o seu quadro de empregados elementos jovens, com suficiente capacidade para se tornarem, eventualmente, elementos de chefia. E muito útil manter contacto com as escolas para atrair os melhores alunos, para que venham trabalhar na emprêsa. A chefia de nivel superior não é recrutada, obrigatòriamente, entre os elementos de chefia ou supervisão inferior. Eventualmente, um empregado que entra na emprêsa nos escalóes inferiores pode chegar à chefia superior, se fôr auxiliado na sua formação, mas não é o caso normal.

Os elementos necessários à formação de um supervisor ou chefe de nivel mais alto começam com as noções básicas de supervisão. Daí por diante os seus conhecimentos técnicos e a sua experiência administrativa devem ser ampliados por um treinamento sistemático, que pode incluir, conforme o caso, atividades dos seguintes tipos:

- freqüência a cursos especializados;

- estágios supervisionados;

- participação em seminários e reuniões profissionais:

- viagem de estudos e observação.

Algumas companhias mantém programas especiais para o desenvolvimento de elementos de chefia. Esses programas incluem uma avaliação continua dos progressos feitos por cada 
um dos participantes do programa e atividades especialmente destinadas a aumentar a sua capacidade de lidar com problemas de ordem geral na vida da emprêsa.

Para as emprêsas de tamanho pequeno, é muito difícil estabelecer um programa de preparação de elementos de chefia isoladamente, pois não possuem os recursos necessários. Nesse caso é preciso utilizar os serviços das entidades da Indústria ou do Comércio e dos estabelecimentos educacionais. O SENAI, por exemplo, está muito preocupado em prestar auxílio nesse sentido.

\section{IV}

\section{COMO ORGANIZAR O TREINAMENTO}

Todos os supervisores e chefes participam, ativamente, do treinamento, mas a responsabilidade pela existência de um bom programa de treinamento deve estar centralizada. Em cada emprêsa, deve haver uma unidade central de treinamento. A organização e a natureza dessa unidade dependem da importância da tarefa a realizar. A primeira coisa a fazer é uma avaliação sumária da tarefa de treinamento na emprêsa.

\section{Estimativa do treinamento a realizar}

Pode-se tomar, como índice básico, que uma emprêsa em funcionamento normal requer 10 horas, por ano, por pessoa, de treinamento corrente. Se houver mudanças constantes no quadro de pessoal, será preciso tomar um indice mais alto. Isto é, um indice médio, o que não quer dizer que cada pessoa deve receber 10 horas de treinamento por ano. Cada categoria de empregados tem necessidades especiais, por exemplo:

- um aprendiz receberá 2 mil horas de treinamento em um ano;

- um supervisor poderá receber 30 horas;

- um engenheiro que fizer um estágio de 2 semanas receberá 80 horas.

Muitos empregados não receberão nenhum treinamento durante alguns periodos.

\section{Pessoal necessário para o treinamento}

Para que o treinamento possa ser levado a efeito com bom resultado é preciso sempre um trabalho preparatório da organização dos cursos, sessões ou estágios de treinamento, e dos materiais auxiliares de instrução. Esse trabalho exige que haja 
pessoas exclusivamente dedicadas ao treinamento, não no sentido de serem organizadores de treinamento. Não é preciso muita gente. A tabela seguinte dará uma idéia aproximada do que é preciso:

\begin{tabular}{|c|c|c|}
\hline $\begin{array}{l}\text { N. } .^{\circ} \text { DE EMPREGADOS DA } \\
\text { EMPRÊSA }\end{array}$ & $\begin{array}{l}\text { N. }{ }^{\circ} \text { DE PESSOAS CUJO } \\
\text { TEMPO E TODO OCUPADO } \\
\text { COM TREINAMENTO }\end{array}$ & $\begin{array}{c}\text { ÁREA NECESSÁRIA PARA A } \\
\text { SEDE Do SERViço }\end{array}$ \\
\hline $\begin{array}{rrr}80 & \text { a } & 150 \\
150 \text { a } & 250 \\
250 \text { a } & 500 \\
500 & \text { a } & 1000 \\
1000 & \text { a } & 5000 \\
5000 & \text { a } & 25000\end{array}$ & $\begin{array}{rrr}1 & \text { a } & 2 \\
2 & \text { a } & 3 \\
4 & \text { a } & 6 \\
6 & \text { a } & 10 \\
8 & \text { a } & 14 \\
12 & \text { a } & 30\end{array}$ & $\begin{array}{rrr}20 \mathrm{~m} 2 & (1 \text { sala }) \\
& 30 \mathrm{~m} 2 & (1 \text { sala }) \\
60 \mathrm{~m} 2 & (2 \text { salas }) \\
& 90 \mathrm{~m} 2 \text { (3 salas) } \\
\left.100 \text { a } 200 \mathrm{~m} 2 \text { (3 a } 4^{\prime \prime}\right) \\
\left.160 \text { a } 300 \mathrm{~m} 2 \text { (4 a } 8^{\prime \prime}\right)\end{array}$ \\
\hline
\end{tabular}

\section{Curso de treinamento}

A despesa total com o treinamento deverá ficar entre $1 \%$ e $3 \%$ da despesa de pessoal da emprêsa, isto é, do total da sua fôlha de pagamento. Uma emprêsa que tenha 100 milhões de cruzeiros de despesa anual de pessoal poderá, pois, gastar entre 1 e 3 milhões de cruzeiros, por ano, com o treinamento. Desta despesa global de treinamento pode-se admitir, nas grandes emprêsas, que $20 \%$ sejam despesas fixas da unidade central do treinamento, e o restante aplicado em projetos especificos de treinamento. Nas emprêsas pequenas é admissivel que tôda a despesa de treinamento esteja na unidade central.

\section{Subordinação administrativa}

A unidade central de treinamento pode ser um "Serviço de Treinamento", um "Departamento", um "Centro", uma "Comissão de Treinamento", ou pode ter qualquer outra denominação simples, mas é essencial que tenha uma categoria hierárquica suficientemente alta, para poder realizar seu trabalho sem depender de chefes de rotina administrativa.

A melhor denominação para o chefe da unidade de treinamento é a de "coordenador", porque dá uma idéia precisa de sua função, que não é a de "professor", mas de coordenador dos planos de treinamento. O coordenador deve estar subordinado, de preferência, à direção-geral da emprêsa, mais é possivel, em casos especiais, a sua subordinação a uma Diretoria técnica ou administrativa.

Compete ao coordenador estimular todos os chefes e supervisores para que cuidem do treinamento de seu pessual e, para isso, êle deve ser capaz de ensinar como se identificam as necessidades de treinamento e como se organizam planos para aten- 
dê-las. Uma vez organizados os planos, deve saber como encaminhá-los para aprovação do orçamento respectivo e como acompanhá-los para garantir o seu sucesso.

\section{Treinamento e seleção}

A utilização da psicologia aplicada para maior eficiência da emprêsa não deve ser considerada como aplicável sòmente na seleção inicial de empregados. U certo é acompanhar continuamente todo o pessoal, procurando conhecer suas qualidades $\mathrm{e}$ deficiências durante tôda sua vida funcional.

Esse acompanhamento deve ser feito por todos os supervisores e chefes, e orientado pelo coordenador de treinamento que nesse caso será coordenador de seleção e treinamento.

Quando se entra no dominio da psicologia não se pode improvisar. E' preciso ter uma orientação técnica segura, o que não é nada fácil. E' preferivel, para a maioria das emprêsas, guiar-se pelo bom senso, e não adotar nenhum sistema ou método que não seja claramente entendido e que tenha sido provado pela experiência. 